\title{
Assessment of Vehicular-Induced Emissions in some Selected Areas in Benin City, Edo State, Nigeria
}

\author{
*11RAJI, WA; ${ }^{2}$ JIMODA, LA; ${ }^{1}$ ODOBOR, JK; ${ }^{2}$ POPOOLA, AO \\ ${ }^{*}$ Department of Chemical and Petroleum Engineering, Igbinedion University Okada, Nigeria. \\ ${ }^{2}$ Department of Chemical Engineering, Ladoke Akintola, University of Technology, Ogbomosho, Nigeria. \\ *Corresponding Author Email: raji.wuraola@iuokada.edu.ng
}

\begin{abstract}
Vehicular emission is a major environmental health problem in the world today especially in developing countries including Nigeria. This study was centered on assessing the vehicular emissions pollutants such as Carbon monoxide (CO), Hydrogen Sulphide $\left(\mathrm{H}_{2} \mathrm{~S}\right)$, Formaldehyde (HCHO) and Total Volatile Organic Compound (TVOC) in Benin City, Edo State, Nigeria. The sampling of the $\mathrm{CO}$ and $\mathrm{H}_{2} \mathrm{~S}$ gaseous pollutants was done using $\mathrm{H}-4 \mathrm{~S}$ gas analyzer while JCG60 gas detector was used to measure TVOC and HCHO. The meteorological parameters were measured with HTC-1 hygrometer thermometer. AQI was calculated to determine the status of the ambient air quality of the study areas. Carbon monoxide concentration obtained from the result ranges from 3.12-16.1 ppm with location $\mathrm{C}$ having the highest amount of $16.1 \mathrm{ppm}$ which exceeds the Federal Environmental Protection Agency (FEPA) standard of $10 \mathrm{ppm}$. The calculated AQI shows that the study areas are all polluted. Continuous measurement and inventory of air pollutants should be encouraged, as this will enable the policymakers to effectively implement control measures on air pollution.
\end{abstract}

\section{DOI: https://dx.doi.org/10.4314/jasem.v25i8.38}

Copyright: Copyright ( 2021 Raji et al. This is an open access article distributed under the Creative Commons Attribution License (CCL), which permits unrestricted use, distribution, and reproduction in any medium, provided the original work is properly cited.

Dates: Received: 10 May 2021; Revised: 28 June 2021; Accepted: 01 July 2021

Pollution due to vehicular emission remains a threat to environmental health problem which is expected to increase reasonably as motor vehicle population increases (Chao et al.,2014; Ji et al.,2018; Mishra et.al., 2019). The growth in vehicles population and the corresponding emissions has led to the degradation of the air quality which in turns affect man and his environment (Xiaonian et al., 2019; Nathaniel and Xiaoli, 2020). Vehicular emission is the direct release of pollutants into the atmosphere and it is the dominant source of gaseous pollutants, such as Carbon monoxide $(\mathrm{CO})$, Nitrogen oxide $\left(\mathrm{NO}_{\mathrm{x}}\right)$, Sulphur oxides $\left(\mathrm{SO}_{\mathrm{x}}\right)$, Total Volatile Organic Compounds (VOCs), Hydrogen sulphides $\left(\mathrm{H}_{2} \mathrm{~S}\right)$, Total Particulate Matters (TPMs), Formaldehyde (HCHO) and water vapour (Schifter et al., 2000; Guttikunda et al., 2012; Abaje et al., 2020; Adeyemi et al., 2020). Several epidemiological studies have shown that human exposure to these pollutants in areas with high level pollutants concentrations constitute severe health problems such as headaches, dizziness, irritation of the eyes, nose and throat, shortness of breath, upper respiratory infections, brain damage, lung cancer, liver and kidney damage, heart diseases and death (CPCB, 2001; Baldacci, 2015; Almeida et al., 2015; Chen et al. 2016; Kolpakova et al., 2017; Robert et al. 2017; Javeria et al. 2018; Sui Zhhu et al 2018; Lei et al. 2020). Nigeria, as a developing nation is also faced with rapid urbanization resulting in uncontrolled growth characterized by lack of physical planning and increasing vehicular traffic which creates high-level traffic related air pollution (Etim, 2016). The reliance on fossil fuel in running vehicles in Nigeria has made vehicular emissions to be at the high side, thereby, aggravating the urban air quality (Muhammad and Yinusa, 2016; Dongqi et al., 2017). Few studies have been carried out in Nigeria on the assessment of vehicular induced emissions and the reports from all the studies show positive relationship between increase in motor vehicles and pollutants concentrations. Abam and Unachukwu (2009) investigated vehicular emissions in some selected areas in Calabar, Nigeria. The study reported high concentrations of $\mathrm{CO}, \mathrm{SO}_{2}$ and $\mathrm{NO}_{2}$ in the study areas and linked the cause to high traffic congestion. Ojo and Awokola (2012), also investigated air pollution from vehicles at intersections on some selected major roads in Ogbomoso, South Western, Nigeria. Four sampling routes were considered with ten sampling points to assess $\mathrm{SO}_{\mathrm{X}}, \mathrm{NOx}$ and $\mathrm{CO}$ concentrations. The pollutants concentrations were highest at intersections with high traffic congestion where long waiting time for vehicles was observed. Furthermore, the air quality in the study areas were rated very poor when compared to air quality level (Air quality index). The outcomes of the studies carried out on vehicular emissions in some selected intersections in Nigeria shows the presence of air pollutants in the sampling locations. Hence, there is a need for air pollution monitoring so as to safeguard the residents in the areas experiencing 
traffic congestion due to increased number of motor vehicles, as this will provide important information on air quality for policymakers for the formulation of effective air pollution control measures. Therefore, the objective of this paper is to assess vehicular emissions pollutants such as Carbon monoxide (CO), Hydrogen Sulphide $\left(\mathrm{H}_{2} \mathrm{~S}\right)$, Formaldehyde $(\mathrm{HCHO})$ and Total Volatile Organic Compound (TVOC) in Benin City, Edo State, Nigeria.

\section{MATERIALS AND METHOD}

Sampling Sites / Sampling Locations: Benin City is an ancient city in South-Western Nigeria (Figure 1) and is bounded by latitude $6^{\circ} 30^{\prime} \mathrm{N}, 6^{\circ} 06^{\prime} \mathrm{N}$ and longitudes $5^{\circ} 30^{\prime} \mathrm{E}$ and $5^{\circ} 45^{\prime} \mathrm{E}$ (Western and Eastern boundaries) and has an estimated land area of 500 square kilometres ( Iwuala and Oriaku, 2019). Benin City in Edo State is the $6^{\text {th }}$ largest city in Nigeria with an estimated population of 1,125,058 (World Population Review, 2019). The influx of vehicles in the city causes high traffic congestion which in turns results to high emissions. Nwankwo et al., (2010) identified Sapele road, Akpakpava road and Airport road as some of the busiest roads with high traffic congestion in Benin City. Figure 2 shows the sampled locations.

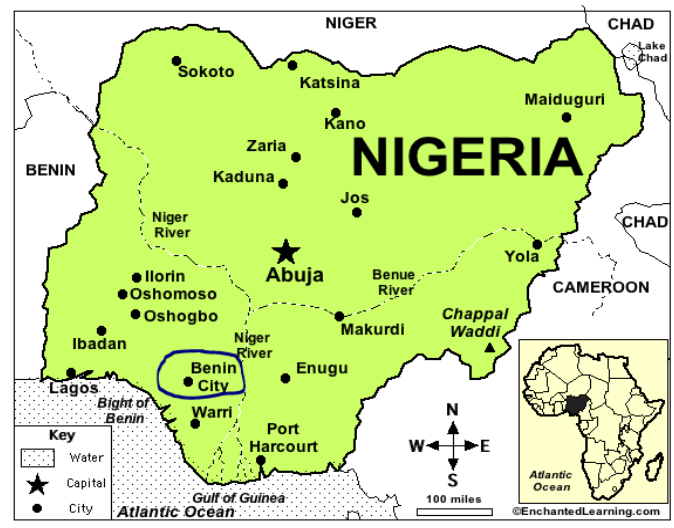

Fig 1: Showing Map of Nigeria and Benin City.

Vehicle Population Density: High traffic congestion is a daily occurrence in the selected study areas owing to their connections to major commercial areas. Although, traffic congestion varies according to the time of the day which necessitates a traffic count in order to ascertain the periods of high pollution as related to traffic congestion. In this study, the traffic count (traffic flow per hour) was done manually over a period of 21 days in the morning, afternoon and evening hours whereby, the vehicles were categorized as cars, buses, trucks and motorcycles (Bike).

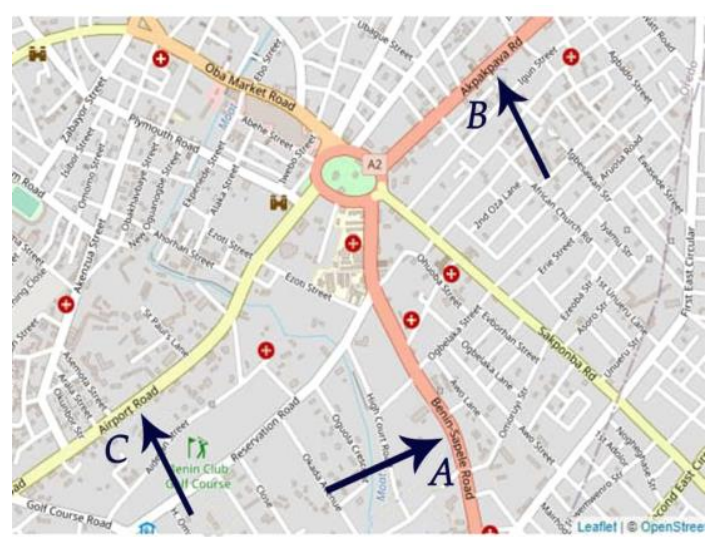

Fig 2: Map showing sampling locations; A (Sapele road), B (Akpakpava road) and C (Airport road) in Benin City, Edo State.

Sampling: The emission of $\mathrm{CO}$ and $\mathrm{H}_{2} \mathrm{~S}$ were monitored with the use of $\mathrm{H}-4 \mathrm{~S}$ gas analyzer while TVOC and HCHO were monitored using JCG60 Gas detector. A handheld hygrometer thermometer, Eagletech HTC-1, was used to measure the meteorological parameters such as temperature and relative humidity. The study was conducted over a period of 21 days during week days, between July 10th and 6th August. The measured concentrations of the pollutants were extrapolated to one hour averaging period using an atmospheric stability formula (Bashar et al., 2009) given in Equation 1. Air quality index (AQI), a technique that determines how clean or polluted the air is, was used to assess the study areas by adopting equation 2 . The impact of the pollutants on human health was also studied via the distribution of questionnaire to the residents around the host environment.

$$
C_{0}=C_{1} X F \quad 1
$$

Where $C_{0}=$ the concentration at the averaging period $t_{0} ; C_{1}=$ the concentration at the averaging period $t_{1}$; $F=$ factor to convert from the averaging period $t_{1}$ to the averaging period to $=\left(\frac{t_{1}}{t_{0}}\right)^{n} ; n=0.28$, the stability dependent exponent

$A Q I=\frac{\text { MEASURED POLLUTANT CONCENTRATION }}{\text { STANDARD CONCENTRATION }} * 1002$

\section{RESULTS AND DISCUSSION}

Table 1 shows the variation in vehicle population density in the study areas in the three locations at an hour averaging period. The volume of cars was found to be the highest in all locations which is an indication that majority are car owners while motorcycles (bikes) are found to be the least in volume because it has been banned in Edo state, Benin City. 
Table 1: Vehicle Population Density

\begin{tabular}{rllllllllllll}
\hline & \multicolumn{4}{c}{ MORNING HOURS } & \multicolumn{4}{c}{ AFTERNOON HOURS } & \multicolumn{3}{c}{ EVENING HOURS } \\
\hline Location & Cars & Buses & Trucks & Bikes & Cars & Buses & Trucks & Bikes & Cars & Buses & Trucks & Bikes \\
A & 1987 & 373 & 41 & 7 & 2091 & 487 & 51 & 21 & 1680 & 276 & 29 & 4 \\
B & 2259 & 713 & 49 & 9 & 1903 & 781 & 57 & 36 & 2389 & 388 & 102 & 28 \\
C & 2227 & 209 & 51 & 25 & 1956 & 321 & 28 & 40 & 3587 & 208 & 35 & 60 \\
\hline
\end{tabular}

Generally, vehicle density reduces in the afternoon hours across the locations owing to lower activities and it is assumed to be the off peak period while the morning and evening hours are marked as peak periods because various activities go on during this periods whereby, workers, business men and women and students leave and return to their homes. Figures 3-6 shows the concentrations of the measured priority pollutants in location A,B and C at morning, afternoon and evening periods. In Figure 3, the concentrations of carbon monoxide ( $\mathrm{CO}$ ) in location $\mathrm{C}$ was found to be the highest in the morning hours irrespective of the lower car density recorded against location B. This could be as a result of the effect of climatic element, temperature. The temperature $\left(39.9^{\circ} \mathrm{C}\right)$ was very high at location $\mathrm{C}$ when compared to location $\mathrm{B}\left(28.4^{\circ} \mathrm{C}\right)$. The increase in temperature increases the emission rate of $\mathrm{CO}$. This observation is in agreement with Nkwocha et al. (2017) findings. All the three locations exceeded the FEPA (1991) allowable limit of CO of $10 \mathrm{ppm}$ and this implies that the study areas are polluted with $\mathrm{CO}$. Hydrogen sulphide $\left(\mathrm{H}_{2} \mathrm{~S}\right)$ is one of the main pollutants emitted from diesel-operated engines. Most trucks in Nigeria use diesel for fueling. The average truck density in location $\mathrm{A}(47), \mathrm{B}(45)$ and $\mathrm{C}$ (55) were few in number when compared to other vehicles. An appreciable number was recorded which was enough to cause pollution. Figure 4 shows the concentration of $\mathrm{H}_{2} \mathrm{~S}$ observed at the study areas. The concentrations were found to be in the range of $0.7-1.8$ ppm which is above the $0.01 \mathrm{ppm}$ limit of Federal Environmental Protection Agency FEPA (1991) ambient air quality standards. The highest value of 1.8 ppm obtained at location $B$ is as a result of higher number of trucks recorded during the evening period. It is therefore advisable that the sulphur content in Nigerian crude be brought to an appreciable amount by ensuring that the imported petrol into the country is of low Sulphur content. The total volatile organic compounds (TVOCs) is an active precursor of tropospheric ozone and a carcinogenic pollutant. The measured concentration values found at the three locations were, A (1.27 ppm), B (0.85 ppm) and C $(0.95 \mathrm{ppm})$ which exceed the Federal Environmental Protection Agency's (FEPA, 1991) standards of 0.08 ppm for an hour averaging period. These results obtained as seen in Figure 5, is in agreement with the report of elevated levels of TVOC in Adeyemi et al., (2020) findings. The average measured values of
Formaldehyde (HCHO) also exceeds the FEPA standard.

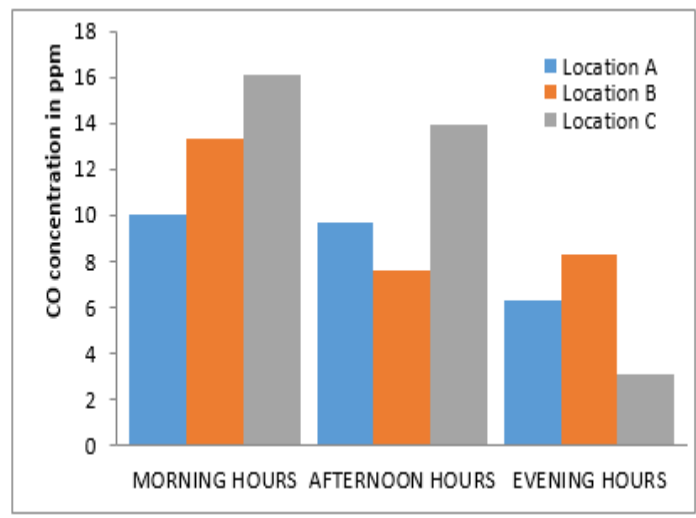

Fig 3: The Average Concentrations of Carbon monoxide at Location A, B \& C.

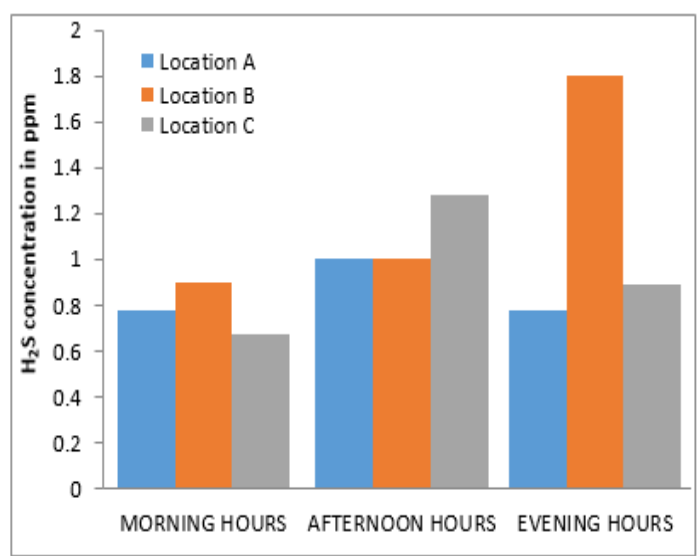

Fig 4: The Average Concentrations of Hydrogen Sulphide at Location A, B \& C.

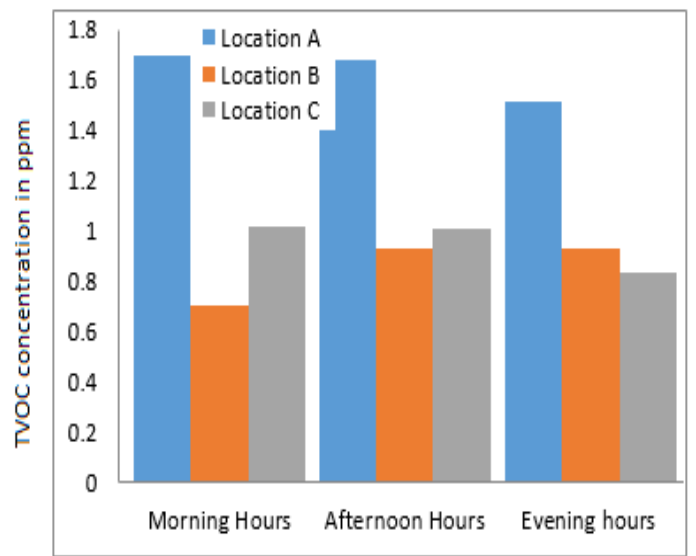

Fig 5: The Average Concentrations of Total Volatile Organic Compound at Location A, B \& C 


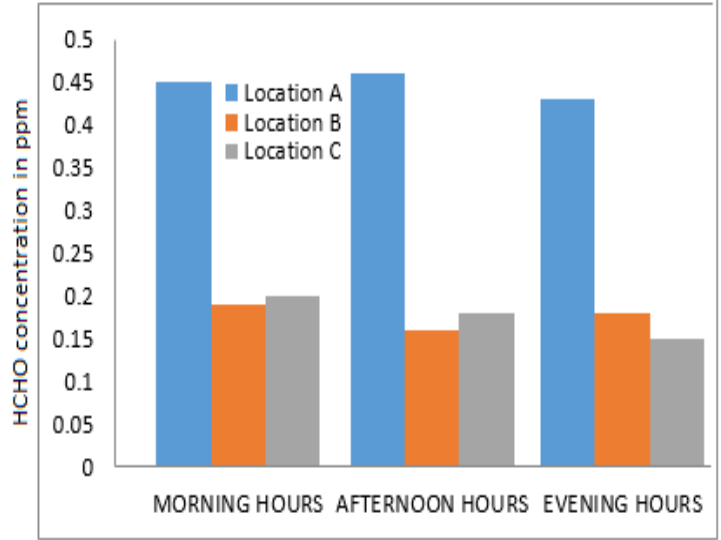

Fig 6: The Average Concentrations of Formaldehyde at Location A, B \& C

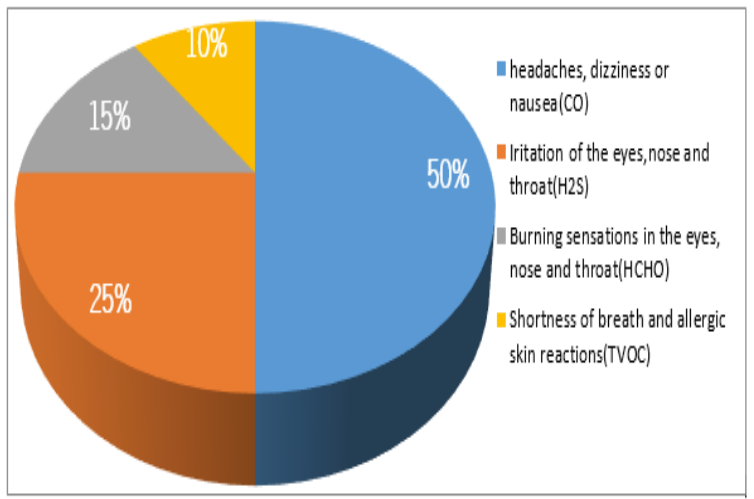

Fig 7: The Evaluation of Health Impact of the Pollutants on human

Air quality index (AQI) is used to obtain and convey information regarding the air quality of a region. According to USEPA (2000), the ambient air pollutants are classified into categories ranging from very good to very poor. From $(0-15) \mathrm{AQI}$ rating is very good, (16 -31) AQI is good, (32 - 49) AQI is moderate, $(50-99) \mathrm{AQI}$ is poor and (100 or above) AQI is very poor. Table 2 depicts the air quality status of the three locations studied in this work. Computed air quality index of location $\mathrm{A}, \mathrm{B}, \mathrm{C}$ shows $90.13 \%, 97.13 \%$ and $110.4 \%$ respectively. Location A and $\mathrm{B}$ air quality is rated poor while Location C is very poor. This is as result of high pollutants concentration in location $\mathrm{C}$ especially carbon monoxide. Hence, the air quality of the three locations is considered not safe for the commuters.

Table 2: AQI rating for ambient air quality of $\mathrm{CO}$ from this study

\begin{tabular}{lll}
\hline LOCATION & AQI value & AQI category \\
\hline A & 90.13 & Poor \\
B & 97.13 & Poor \\
C & 110.4 & Very poor \\
\hline
\end{tabular}

The impact assessment of pollutants on human health of the people living and trading around the study areas was carried out based on the distribution of questionnaires, depicted in the pie chart in figure 7. About $50 \%$ of the commuters often experience headaches, dizziness or nausea which are symptoms of carbon monoxide inhalation while $25 \%$ complained of eyes, nose and throat irritation which is also an indication of $\mathrm{H}_{2} \mathrm{~S}$ exposure. $10 \%$ experiences shortness of breath and skin allergy reaction as a result of being exposed to total volatile organic compounds.

Conclusion: The outcome of the assessment of CO, $\mathrm{H}_{2} \mathrm{~S}, \mathrm{HCHO}$ and TVOCs in Benin City, Edo State, Nigeria, showed that all the pollutants concentrations in the sampling locations exceeded the Nigerian local standard as stipulated in FEPA (1991). The ambient air quality of the three locations are rated poor based on the calculated Air Quality Index (AQI). Hence, it is important to engage in continuous air monitoring, as this will serve as a guide for governmental bodies to plan actions on air quality management such as the decongestion of the traffic-related junctions in the host environs.

\section{REFERENCES}

Abaje IB; Yusuf B; Ahmad SA (2020). A Review of Air Quality and Concentrations of Air pollutants in Nigeria. J. Appl. Sci. Environ. Manage.t 24(2): 357364.

Abam F.I., Unachukwu G.O. (2009). Vehicular Emissions and Air Quality Standards in Nigeria. Euro. J. Sci. Res. 34 (4) :550-560.

Adeyemi A.J, Kanee R.B., Edokpa D. O., Ede P. N. (2020). Total volatile organic compounds concentration at selected automobile repair workshop centres in Port Harcourt, Nigeria. Inter. Res. J. Publ. Environ. Health, 7 (5) :190-196.

Almeida Daniela S. de, Jorge A. Martins, Lourenço H. B. Vidotto, Leila D. Martins (2015). Study of Potential Health Damage Caused by Ultrafine Particles using a Pulmonary Deposition Model. J. Geosci. Environ. Pro. 3 : 67-71

Baldacci S, Maio S, Cerrai S, et al (2015). Allergy and asthma: Effects of the exposure to particulate matter and biological allergens. Resp. Med., 109: 10891104.

Central Pollution Control Board (CPCB) (2001) Environmental Standards for Ambient Air, Automobiles, Fuels, Industries and Noise, Pollution Control Law Series; PCLS/4/2000-2001. CPCB Delhi. 
Design science to improve air quality in high-density cities. 30th Inter. Plea Conf. December, Cept University, Ahmedabad.: 1-9.

Chen, K.Y., Chuang, K.J., Liu, H.C., et al, (2016). Particulate matter is associated with sputum culture conversion in patients with culture-positive tuberculosis. Ther. Clin. Risk Manage. 12: 41-46

Dongqi Wen, Wenjuan Zhai, Sheng Xiang, Zhice Hu, Tongchuan Wei , Kenneth E. Noll (2017). Nearroadway monitoring of vehicle emissions as a function of mode of operation for light-duty vehicles. J. Air Wast. Manage. Assoc. 67:12291239.

Guttikunda Sarath K, RahulGoel (2013). Health impactsofparticulatepollution in a megacity-Delhi, Ind. Environ. Dev. $6: 8-20$.

FEPA.Nigerian Standard on Environmental Parameters and Control usage (1991).

Mishra A. Kushwaha, Devesh Aggrawal, Ankit Gupta (2019).Comparative emission study by real-time congestion monitoring for stable pollution policy on temporal and meso-spatial regions in Delhi. $J$. Clean. Pro. 224: 465-478.

Muhammad Dayyab Garba, Yinusa M.,(2016). Assessing gaseous pollutants and air quality in some areas of Kano metropolis, Kano, Nigeria. Trans. Eco. Environ. 203: 125-134.

Nathaniel Mopa Wambebe , Xiaoli Duan (2020). Air Quality Levels and Health Risk Assessment of Particulate Matters in Abuja Municipal Area, Nigeria. Atmos. 11: 1-15

Nwankwo, Wilson, Akinola S. Olayinka, Kingsley E. Ukhurebor (2019). The Urban Traffic Congestion Problem in Benin City And The Search For An ICTImproved Solution. Inter. J. Sci. Technol. Res. 8 (12):65-72.

Nkwocha A.C., Ekeke I.C., Kamalu C.I.O., Kamen F.L., Uzondu F.N., Dadet W.P., Olele P.C. (2017). Environmental Assessment of Vehicular Emission in Port-Harcourt City, Nigeria. Inter. J. Environ. Agric. Biotechnol. (IJEAB), 2 (2) : 905-911.

Iwuala I.S. and Oriaku T.O. (2019). Assessment of Vehicular Carbon Dioxide Emission at Major Road Intersections in Benin City, Edo State Nigeria. Nigeria Annual International Conference and Exhibition held in Lagos, Nigeria. Soc. Petrol. Engrs. (SPE) :5-7.
Javeria Zaheer, Jongho Jeon, Seung-Bok Lee, Jin Su Kim (2018). Effect of Particulate Matter on Human Health, Prevention, and Imaging Using PET or SPECT. Progr. Med. Phys., 29 (3): 81-89.

Ji Ying, Xiaofei Qin, Bo Wang, Jian Xu, Jiandong Shen, Jianmin Chen, Kan Huang, Congrui Deng, Renchang Yan, Kaier Xu, and Tian Zhang (2018). Counteractive effects of regional transport and emission control on the formation of fine particles: a case study during the Hangzhou G20 summit. Atmos. Chem. Phys. 18 : 13581-13600

Kolpakova AF, Sharipov RN, Kolpakov FA. (2017).Air pollution by particulate matter as the risk factor for the cardiovascular diseases. The Silb. J. Cli. Exper. Med. 96: 133-137.

Ojo O.O. S, Awokola O.S. (2012). Investigation of Air Pollution from Automobiles at Intersections on Some Selected Major Roads in Ogbomoso, South Western, Nigeria .J. Mech. Civ. Engr. (IOSRJMCE), 1 (4): 31-35.

Robert J. B., Lisa Pascopella, Donald G. Catanzaro, Pennan M. Barry, Paul B. English, Mark R. Segal, Jennifer Flood. Dan Meltzer, Brenda Jones, John Balmes, Payam Nahid (2017). Traffic-Related Air Pollution and All-Cause Mortality during Tuberculosis Treatment in California. Environ. Hlth. Pers. 125 (2):26-38.

Schifter I., L. Díaz, E. López-Salinas, F. Ramos, S. Avalos, G. López-Vidal, M, Castillo (2000). Estimation of Motor Vehicle Toxic Emissions in the Metropolitan Area of Mexico City. Environ. Sci. Technol., 34 (17): 3606-3610

Sui Zhu, Lan Xia , Jianlin Wu, Shaobing Chen, Fei Chen , Fangfang Zeng, Xiuwei Chen, Chuang Chen, Yong Xia , Xing Zhao, Juying Zhang (2018). Ambient air pollutants are associated with newly diagnosed tuberculosis: A time-series study in Chengdu, China. Sci. Tot. Environ. 631-632: 47-55.

World Population Review (2019). Nigeria Population 2019. Avalaible at http://worldpopulationreview.com/countries/nigeria population/. [Accessed 10 November 2020]

Xiaonian Shan, Xiaohong Chen, Wenjian, Jianhong Ye (2019). Evaluating Urban Bus Emission Characteristics Based on localized MOVES using sparse GPS data in Shanghai, China. Sustainability, 11(10) : 4-26. 